\title{
PERKEMBANGAN PENGUMPULAN ZAKAT PADA BAZNAS KABUPATEN TANAH DATAR PERIODE 2010 s.d. 2014
}

\author{
Rizal Fahlefi \\ Fakultas Ekonomi dan Bisnis Islam IAIN Batusangkar \\ J1. Jenderal Sudirman No. 137, Lima Kaum Batusangkar \\ e-mail: rizalfahlefi735@yahoo.co.id
}

\begin{abstract}
Collecting zakat (divine tax) is one of the main responsibilities of amil (the collector) of zakat. In fulfilling this kind of responsibility, BAZNAS of Tanah Datar Regency has done is successfully. This study, therefore, aimed figuring out the zakat collecting growth in BAZNAS of Tanah Datar Regency during 2010-2014 periods in terms of the nominal, source, and efforts made in collecting the rakat. To achive the goals, this study employed case study. The findings showed that the numbers of rakat collected during the period increased significantly with a total of more than IDR 34.44 billions. The increase was much far above the average that could be achieved nationally. In term of source of zakat, there was extended sources from profession zakat to other sources, such as trade and services zakat. In order to support its efforts to collect zakat successfully, BAZNAS of Tanah Datar Regency made continuous efforts to increase Zakat Collecting Unit (UPZ), established marketing team, distributed marketing tools, dan conducted massive zakat socialization
\end{abstract}

Kata kunci: pengumpulan, zakat, BAZNAS Kabupaten Tanah Datar

\section{PENDAHULUAN}

$Z$ akat sesungguhnya merupakan sarana untuk menciptakan keadilan sosial dan mengentaskan kemiskinan. Keadilan sosial yang diciptakan oleh zakat adalah melalui penyebaran harta kepada orangorang miskin, sehingga harta kekayaan itu tidak hanya berhenti pada kantong-kantong orang yang kaya saja. Selanjutnya, zakat juga mampu mengentaskan kemiskinan melalui distribusi harta zakat kepada setiap orang yang berhak agar orang tersebut dapat memenuhi hak-hak dasarnya (Fahham, 2011: 9). Tujuan mulia dari ibadah zakat tersebut akan terwujud jika zakat disalurkan secara benar, yaitu melalui amil yang legal serta ditunjuk oleh pemerintah daerah setempat.

Adapun rahasia di balik ditugaskannya para amil antara lain agar terciptanya jaminan bagi si fakir akan haknya, untuk memelihara kehormatan mereka, lebih memungkinkan distribusi zakat yang lebih tepat dan tidak terkonsentrasi pada sebagian orang saja. Di samping itu, ada beberapa sasaran zakat yang berhubungan dengan kemaslahatan bersama kaum Muslimin seperti dalam mengorganisasikan jihad fi sabilillah dan mempersiapkan para da'i untuk menyampaikan risalah Islam, sehingga baik pengumpulannya maupun pendistribusiannya tidak bisa dilakukan secara perorangan (Al-Qaradhawi dalam Baga, 1997: 23). 
Untuk realitas di era modern ini, kelompok amil akan lebih optimal jika diperankan oleh intermediary system, atau badan dan lembaga amil zakat. Dengan demikian tingkat optimalisasi profesionalismenya akan melihat amil sebagai kelembagaan dan amil sebagai person, keduanya mewakili Sang Maha Pemurah untuk mengapresiasikan pemahaman khalifah di muka bumi akan makna dari kepemilikan materi (Mufraini, 2008: 194). Salah satu fatwa hasil symposium zakat internasional yang diadakan di Bahrain 1994 menyebutkan bahwa badan-badan dan lembaga-lembaga zakat yang dibentuk dewasa ini merupakan bentuk modern yang memperkaya khazanah sistem pengelolaan zakat dalam tata hukum Islam (Ridlo, 2006: 32).

Di Indonesia, pengelolaan zakat untuk skala nasional semakin baik sejak disahkannya UU Nomor 38 Tahun 1999 tentang Pengelolaan Zakat yang ditindaklanjuti dengan Keputusan Menteri Agama (KMA) Nomor 581 tahun 1999 tentang Pelaksanaan UU Nomor 38 tahun 1999 dan Keputusan Dirjen Bimas Islam dan Urusan Haji Nomor D/291 tahun 2000 tentang Pedoman Teknis Pengelolaan Zakat. Meskipun dalam implementasinya menemui banyak kendala di lapangan, namun lahirnya UU Nomor 38 Tahun 1999 telah memfasilitasi hadirnya lembaga pengelola zakat bentukan pemerintah yang disebut Badan Amil Zakat (BAZ).

Jika sebelum dekade 1990-an pengelolaan zakat masih bersifat terbatas, tradisional dan individual, maka pasca dekade tersebut pengelolaan zakat memasuki era baru, dimana unsur-unsur profesionalitas dan manajemen modern telah diterapkan. Salah satu indikatornya adalah semakin banyaknya bermunculan Badan Amil Zakat yang baru dengan pendekatan-pendekatan yang baru pula (Surur, 2006: 161).

Hal tersebut menunjukkan bahwa kesadaran berzakat di kalangan kaum Muslimin di Indonesia telah mengalami kemajuan. Namun perkembangan yang menggembirakan ini belum menyentuh seluruh lapisan masyarakat kaum Muslimin. Berdasarkan beberapa pengalaman yang telah dilakukan, banyak kendala yang dihadapi dalam rangka mengumpulkan zakat baik dari kalangan Pegawai Negeri Sipil maupun masyarakat umum. Oleh karena itu, diperlukan kiatkiat atau strategi khusus untuk menumbuhkan kesadaran berzakat di kalangan kaum muslimin (Fakhruddin, 2008: 309-310).

Seiring dengan perkembangan masyarakat dan kebutuhan akan produk hukum, maka pada tahun 2011 pemerintah mengesahkan Undang-Undang Nomor 23 Tahun 2011 tentang Pengelolaan Zakat. Dalam UU Nomor 23 Tahun 2011 dijelaskan bahwa untuk melaksanakan pengelolaan zakat, pemerintah membentuk Badan Amil Zakat Nasional (BAZNAS) yang berkedudukan di ibu kota negara. Dalam rangka pelaksanaan pengelolaan zakat pada tingkat provinsi dan kabupaten/ kota dibentuk BAZNAS propinsi dan BAZNAS kabupaten/ kota. Undang-Undang Nomor 23 Tahun 2011 tentang Pengelolaan Zakat diperkuat dengan dikeluarkannya Peraturan Pemerintah Republik Indonesia Nomor 14 Tahun 2014 tentang pelaksanaan pengelolaan zakat.

BAZNAS Kabupaten Tanah Datar dibentuk oleh pemerintah kabupaten Tanah Datar melalui SK Bupati dan berkedudukan di ibu kota kabupaten. Sejak berdiri tahun 1999, BAZNAS Kabupaten Tanah Datar telah melalui beberapa periode kepengurusan. Pada awalnya lembaga ini disebut BAZIS, kemudian berubah nama menjadi BAZ, 
sampai akhirnya disebut BAZNAS sejak tahun 2011.

BAZNAS kabupaten/ kota melaksanakan tugas dan fungsi BAZNAS di kabupaten/ kota tersebut (UU RI Nomor 23 Tahun 2011 Tentang Pengelolaan Zakat). Dengan demikian, BAZNAS Tanah Datar juga berkewajiban melaksanakan tugas dan fungsi BAZNAS di kabupaten Tanah Datar. Salah satu tugas tersebut adalah tugas pengumpulan zakat dari segenap potensi zakat yang ada di kabupaten ini.

Pengelolaan zakat oleh lembaga pengelola zakat, apalagi yang memiliki kekuatan hukum formal, akan memiliki beberapa keuntungan, salah satunya untuk menjamin kepastian dan disiplin pembayar zakat (Hafidhuddin, 2006: 79). Dalam hal ini, BAZNAS Kabupaten Tanah Datar sebagai lembaga pengelola zakat yang memiliki kekuatan hukum formal diharapkan mampu menjamin kepastian dan disiplin pembayar zakat (muzaki) tersebut karena akan berdampak positif terhadap pengumpulan zakat.

Penelitian ini bertujuan untuk mengetahui perkembangan pengumpulan zakat pada BAZNAS Kabupaten Tanah Datar selama periode 2010-2014. Perkembangan yang dimaksud adalah dari aspek nominal zakat yang berhasil dikumpulkan, sumbersumber zakat, jumlah muzaki yang mempercayakan penyaluran zakatnya melalui BAZNAS, dan upaya-upaya yang terus dikembangkan dalam proses pengumpulan zakat.

\section{METODE PENELITIAN}

Metode penelitian yang digunakan dalam penelitian ini adalah metode studi kasus dengan pendekatan kualitatif. Sumber data penelitian ini terdiri dari pengurus BAZNAS Tanah Datar, tenaga sekretariat, dan dokumen-dokumen yang terkait meliputi dokumen laporan tahunan, Standar Operasional Prosedur (SOP), Surat Keputusan (SK), dan database yang dimiliki.

Adapun teknik pengumpulan data yang digunakan adalah wawancara dan dokumentasi. Peneliti melakukan analisis data selama proses dan setelah selesainya pengumpulan data dengan langkah-langkah analisis yaitu (a) reduksi data, (b) displai data, dan (c) menarik kesimpulan dan verifikasi. Validitas dan reliabilitas data dilakukan dengan triangulasi terhadap sumber data dan metode pengumpulan data.

\section{PEMBAHASAN}

\section{Kajian Teori}

Masyarakat menyalurkan zakatnya kepada pengelola zakat karena percaya kepada organisasinya. Semakin tinggi tingkat sosial masyarakat yang merupakan calon donatur potensial, maka semakin tinggi pula tingkat kepercayaan yang harus dibangun oleh pengelola zakat agar bisa mendapatkan dana zakat dari mereka (Yani, 2008: 16). Agar pengelolaan zakat berjalan dengan baik, maka organisasi pengelola zakat harus menerapkan prinsipprinsip good organization governance (tata kelola organisasi yang baik).

1. Amanah. Zakat merupakan salah satu rukun Islam yang bicara tentang kemasyarakatan. Kewajiban berzakat bagi para muzaki memiliki landasan syar'i yang kuat dan jelas.

2. Transparan. Transparan di sini diartikan sebagai suatu kewajiban BAZ selaku amil 
untuk mempertanggungjawabkan tugasnya kepada publik baik kepada para muzaki, mustahik maupun stakeholder lainnya. Bentuk transparansi ini dapat dilakukan melalui publikasi laporan di media cetak, auditable oleh akuntan publik dan laporan tahunan.

3. Profesional. Amil zakat merupakan profesi. Oleh karenanya, amil mesti profesional yang dicirikan dengan bekerja full time, memiliki kompetensi, amanah, jujur, leadership, jiwa entrepreneurship, dan lain-lain. Dengan pengelolaan yang professional, amanah muzaki tertunaikan, mustahik diberdayakan. (Mufraini, 2008: 198).

Kepedulian amil untuk menangani zakat secara profesional dimaksudkan untuk mengelola (mengumpulkan dan mendistribusikan) kekayaan kaum muslim yang bersumber dari para aghniya dan disalurkan kepada masyarakat yang membutuhkan serta memberikan akselerasi bagi mereka yang berjuang menegakkan keadilan dan pembebasan. Ini dimaksudkan agar kekayaan tidak menumpuk pada kaum pemilik modal semata (Muhammad \& Abu Bakar, 2011: 121).

Dengan demikian, secara garis besar tugas amil zakat dapat dikategorikan menjadi dua kelompok, yaitu tugas-tugas dalam pengumpulan zakat dan tugastugas dalam pendistribusiannya. Dalam pengumpulan zakat, amil zakat berhubungan dengan para muzaki, sedangkan dalam pendistribusiannya amil zakat berhubungan dengan para mustahik.

Dalam aspek pengumpulan zakat, lembaga-lembaga amil zakat harus menerapkan marketing strategy sebagaimana lembaga bisnis yang mengedepankan marketing. Lembaga-lembaga amil zakat dalam menggaet muzaki juga harus menerapkan prinsip customer oriented dan menggandeng konsultan Marketing and Comunication dalam mempertajam strategi pengumpulan zakat. Lembagalembaga amil zakat melakukan strategi penguasaan pasar bebas sebagaimana dalam dunia bisnis. Siapa yang kreatif, inovatif dan profesional akan memenangkan pasar. Prinsip inilah yang kemudian membuat lembaga amil zakat dapat bertahan dan semakin banyak dipercaya oleh masyarakat. Aspek lain yang menjadi kekuatan dari manajemen lembaga amil zakat adalah aspek komunikasi kepada publik. Setiap aktivitas yang dilakukannya harus dimuat oleh media dalam rangka membangun awareness masyarakat terhadap lembaga amil zakat tersebut (Surur, 2006: 163).

Pengumpulan zakat dilakukan oleh amil zakat dengan cara menerima atau mengambil dari muzaki atas dasar pemberitahuan muzaki. Amil dapat bekerja sama dengan bank dalam mengumpulkan zakat muzaki (Fakhruddin, 2008: 309). Pengumpul zakat bertugas mendata dan menetapkan muzaki. Dalam hal ini para pengumpul menetapkan jenis-jenis harta yang wajib kena zakat dan jumlah yang harus mereka bayar. Kemudian mengambil dan mengelolanya untuk selanjutnya diserahkan kepada para petugas yang mendistribusikan. Para pengumpul juga harus paham tentang hukum zakat, misalnya hal-hal yang berkaitan dengan jenis harta, kadar nishab, haul dan sebagainya (Shihab, 1999: 328-329).

Menurut Mufraini (Mufraini, 2008: 195), terkait dengan pengumpulan tugas amil zakat adalah melakukan pendataan muzaki dan mustahik, melakukan pembinaan, managih, mengumpulkan dan menerima zakat, mendoakan muzaki saat menyerahkan zakat kemudian menyusun penyelenggaraaan sistem adiministratif dan manajerial dana zakat yang terkumpul. Dalam Fatwa Majelis Ulama Indonesia Nomor 8 tahun 2011 tentang Amil Zakat dinyatakan 
bahwa Amil zakat bertugas melakukan penarikan/pengumpulan zakat yang meliputi pendataan wajib zakat, penentuan objek wajib zakat, besaran nisab zakat, besaran tarif zakat, dan syarat-syarat tertentu pada masing-masing objek wajib zakat.

Peran para amil zakat selaku pengemban amanah dalam pengelolaan dana zakat khususnya dalam pengumpulan tidak akan dapat berjalan dengan baik tanpa dukungan dari penguasa, dalam hal ini pemerintah. Hal ini disebabkan karena para amil pada hakikatnya adalah wakil penguasa dalam hal pemungutan zakat tersebut. Hadi (2010: 82) menegaskan bahwa sosialisasi pemerintah terkait dengan organisasi pengelolaan zakat dalam kehidupan masyarakat mutlak diperlukan.

Pengelolaan zakat tersebut pada hakikatnya diserahkan kepada pemerintah, sebagaimana perintah Allah dalam firman-Nya "khudz min amwalihim" (ambillah zakat dari harta mereka). Para ahli fikih menafsirkan ayat di atas, bahwa kewenangan untuk melakukan pengambilan zakat dengan kekuatan hanya dapat dilakukan oleh pemerintah. Oleh sebab itu di antara pemahaman para fuqaha' ialah wajibnya pemerintah melakukan pungutan zakat dan kemudian menyalurkannya kepada asnaf sesuai dengan ketentuan yang telah ditetapkan syariah (Ridlo, 2006: 31; Surur, 2006: 157).

Beberapa ulama modern bahkan cenderung mengandalkan peranan pemerintah tersebut dalam pengumpulan zakat karena:

1. Telah banyak orang yang meninggalkan kewajiban zakat atas semua jenis hartanya, baik yang zahir maupun yang batin. Hendaklah para penguasa mengambilnya secara paksa.

2. Secara umum jenis-jenis harta yang ada sekarang ini adalah harta zahir, yang bisa diketahui oleh orang lain selain pemiliknya sendiri (misalnya simpanan di bank sudah dapat diketahui pihak lain dengan mudah) (Baga, 1997: 24).

\section{Hasil Penelitian dan Pembahasan}

Pengumpulan zakat merupakan salah satu tugas utama BAZNAS. Dalam pengumpulan zakat tersebut, BAZNAS Kabupaten Tanah Datar melakukannya melalui beberapa jalur penerimaan sebagai berikut:

1. Penerimaan zakat via bank penerima; yaitu rekening bank yang ditunjuk sebagai rekening bagi muzaki yang menyalurkan zakat secara langsung via bank.

2. Penerimaan zakat via kotak infak; kolektor kotak infak adalah amil yang berkedudukan di kantor BAZNAS kabupaten yang bertugas mengumpulkan zakat via kotak infak minimal satu kali dua bulan dan menyerahkan Bukti Setoran Zakat (BSZ) kepada penanggung jawab kotak infak, selanjutnya kolektor kotak infak menyetorkannya kepada Staf Bagian Pengumpulan pada BAZNAS dengan melampirkan BSZ.

3. Penerimaan zakat via marketing; yaitu amil yang berkedudukan di kantor BAZNAS kabupaten yang bertugas menerima zakat dari muzaki perorangan dan memberikan BSZ kepada muzaki, lalu zakat disetorkan kepada UPZ Konter Kantor BAZNAS dengan melampirkan BSZ.

4. Penerimaan zakat via UPZ Konter Kantor BAZNAS; yaitu UPZ konter yang berkedudukan di kantor BAZNAS yang bertanggungjawab menerima zakat dari UPZ kabupaten (UPZ yang berkedudukan di instansi kabupaten) dan perorangan, 
selanjutnya menyetorkannya ke rekening BAZNAS di bank penerima.

5. Penerimaan zakat via UPZ kecamatan; yaitu UPZ yang berwenang mengkoordinir pengumpulan zakat dari sub-UPZ (Sub-UPZ Sekolah, Sub-UPZ Masjid) dan perorangan di wilayah kecamatan masing-masing. Selanjutnya UPZ kecamatan menyetorkan zakat di kecamatan masingmasing ke rekening BAZNAS di bank penerima (BAZNAS Tanah Datar, Standar Operasional Prosedur (SOP) Pengumpulan, 2014).

Dalam bidang pengumpulan tersebut, terdapat perkembangan yang cukup pesat pada BAZNAS Kabupaten Tanah Datar.
Jumlah zakat yang berhasil dikumpulkan senantiasa meningkat dari tahun ke tahun, dengan peningkatan yang sangat signifikan. Pada tahun 2010 jumlah zakat yang telah dikumpulkan oleh BAZNAS Tanah Datar Rp. 4,27 milyar, tahun 2011 Rp. 5,06 milyar, tahun 2012 Rp. 7,86 milyar, tahun 2013 Rp. 8,48 milyar, dan tahun 2014 Rp. 8,77 milyar. Total keseluruhan dalam jangka lima tahun terakhir adalah lebih dari Rp. 34,44 milyar. (Laporan Tahunan BAZNAS Tanah Datar).

Peningkatan jumlah zakat yang terkumpul dalam kurun waktu lima tahun tersebut dapat digambarkan sebagai berikut:

\section{Tabel 1. Jumlah Pengumpulan Zakat pada BAZNAS Tanah Datar Periode 2010-2014}

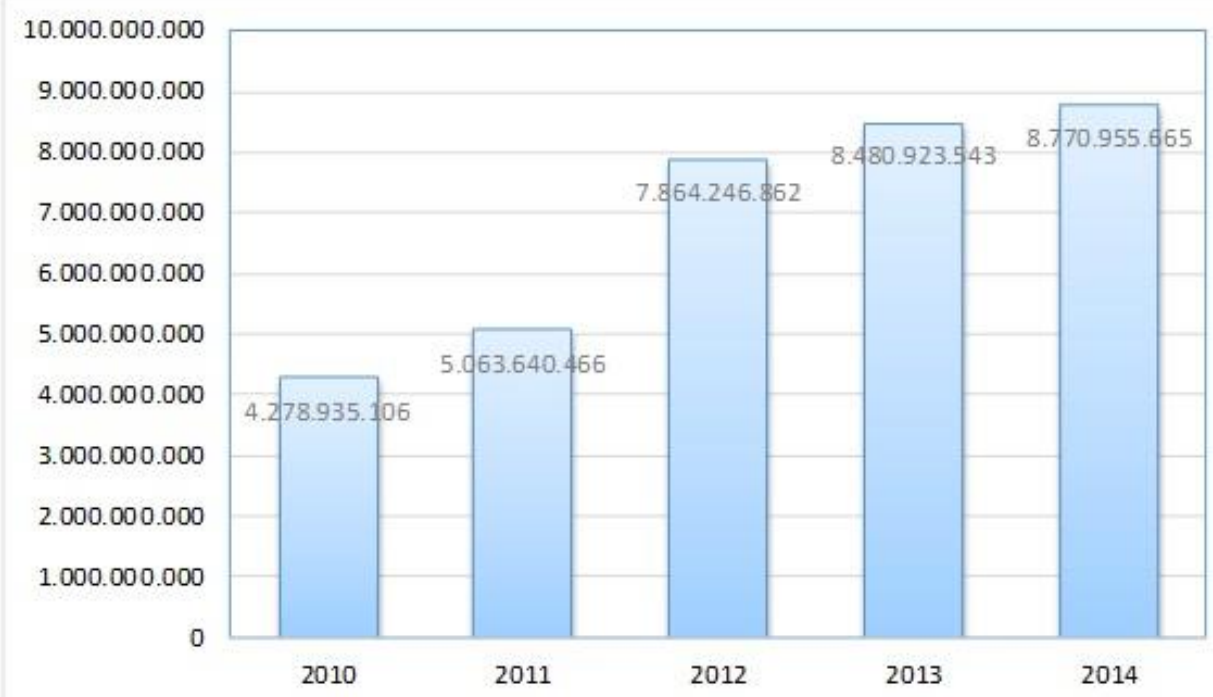

Dalam kurun waktu lima tahun, BAZNAS Tanah Datar mampu mengumpulkan zakat sebesar Rp. 34,44 milliar lebih. Jumlah tersebut bukan jumlah yang kecil, dengan jumah zakat tersebut telah mampu membantu sekian banyak mustahik dalam mengatasi kesulitan ekonomi yang mereka hadapi (zakat konsumtif) sekaligus diharapkan dapat meningkatkan kesejahteraannya (zakat produktif). Bahkan dengan dana zakat sebesar itu, BAZNAS Kabupaten Tanah Datar telah ikut berkontribusi dalam memajukan pendidikan di daerah ini, dengan memberikan beasiswa kepada siswa dan mahasiswa dari keluarga kurang mampu dan juga telah membangun puluhan rumah bagi keluarga miskin sehingga dapat menempati rumah yang nyaman dan layak huni. BAZNAS Kabupaten Tanah Datar juga telah banyak membantu biaya pengobatan dan menyelamatkan keluarga terlantar 
dengan memberikan subsidi rutin setiap bulannya.

Di samping peningkatan jumlah zakat yang terkumpul, BAZNAS Kabupaten Tanah Datar juga berupaya memperluas sektor-sektor yang menjadi sumber zakat. Meskipun zakat profesi khususnya zakat PNS tetap menjadi unggulan, namun beberapa sumber zakat lain harus dijangkau. Pengumpulan zakat dari sumber-sumber lainnya tersebut memerlukan upaya yang lebih kompleks dari BAZNAS karena dihadapkan pada beberapa kendala. Data muzaki cenderung lebih sulit didapatkan, jumlah zakat juga lebih sulit untuk dihitung, belum lagi muzaki tersebar pada wilayah yang cukup luas. Beberapa hal tersebut menjadi kendala bagi BAZNAS dalam menghimpun zakat dari sumber-sumber lain.

Meskipun demikian, BAZNAS Tanah Datar tetap mengupayakan perluasan sumber zakat tersebut. Melalui upaya maksimal, beberapa sumber zakat yang lain mulai mampu diserap seperti dari sektor perdagangan dan jasa. Zakat dari sektor perdagangan meliputi pedagang-pedagang di pasar Batusangkar, sedangkan zakat dari sektor jasa seperti jasa perhotelan.

Untuk kelancaran para muzaki dalam menyalurkan zakat serta terkoordinirnya pengumpulan zakat dengan baik, pengurus BAZNAS terus menambah jumlah UPZ. UPZ adalah satuan organisasi yang dibentuk oleh BAZNAS di semua tingkat dengan tugas untuk memudahkan muzaki dalam menyalurkan zakat. Fungsi UPZ adalah perpanjangan tangan BAZNAS Kabupaten, yang bertugas sebagai pengumpul zakat di masing-masing unit/wilayah.

BAZNAS membentuk UPZ pada masing-masing SKPD, instansi vertikal, BUMN, BUMD, kecamatan, perguruan tinggi, sekolah, madrasah, dan masjid masjid yang dianggap sudah siap dan layak dibentuk UPZ. Pengurus UPZ ditetapkan melalui Surat Keputusan (SK) Ketua BAZNAS Kabupaten Tanah Datar. Prosedur pembentukan UPZ dilakukan dengan langkah-langkah sebagai berikut: a) melakukan sosialisasi tentang zakat, b) melakukan pendataan berbagai instansi pemerintah dan lembaga lainnya yang dianggap siap dan layak, c) membangun kesepakatan dengan pimpinan instansi dan lembaga tersebut untuk membentuk UPZ, dan d) membuat dan mengeluarkan SK pembentukan UPZ (SK Ketua BAZNAS Tanah Datar Tentang Sub UPZ, 2013).

Keberadaan unit-unit ini sangat membantu BAZNAS kabupaten Tanah Datar dalam proses pengumpulan zakat karena dapat menjangkau sumber-sumber zakat yang sulit dijangkau dan tidak terkoordinir, sehingga pada akhirnya dapat meningkatkan jumlah dana zakat yang terkumpul secara signifikan. UPZ hanya bertanggung jawab untuk menerima zakat yang dibayarkan oleh muzaki, kemudian zakat yang sudah terkumpul segera diserahkan kepada devisi pengumpulan BAZNAS, baik secara langsung maupun melalui rekening bank yang sudah ditunjuk.

Untuk zakat PNS, penyerahan zakat dilakukan melalui pemotongan gaji oleh bendaharawan gaji atas nama UPZ, karena BAZNAS sudah menyiapkan surat kesediaan pemotongan gaji sebesar zakat yang dikeluarkan. Bendaharawan gaji menyerahkan zakat SKPD atau instansi terkait melalui sarana yang telah disediakan oleh BAZNAS kabupaten, yakni melalui kantor BAZNAS, relawan BAZNAS, atau melalui beberapa rekening bank yang telah ditunjuk oleh BAZNAS.

Untuk zakat dari masyarakat umum dihimpun dengan beberapa cara. Sebagian muzaki menyalurkan zakatnya melalui UPZ 
masjid, tetapi ada juga muzaki yang mengantar langsung zakatnya ke kantor BAZNAS Tanah Datar atau mentransfernya melalui rekening BAZNAS, dan sebagian lainnya menyalurkan zakat melalui pengurus atau petugas lapangan BAZNAS baik dengan sistem dititipkan ataupun dijemput.

Di samping pembentukan UPZ, BAZNAS Tanah Datar juga membentuk tim marketing untuk perluasan wilayah pengumpulan zakat ke muzaki swasta. Selain untuk pengumpulan, tim ini juga bertugas untuk mensosialisasikan program-program BAZNAS Kabupaten Tanah Datar kepada masyarakat untuk memberikan pemahaman dan meyakinkan masyarakat untuk menyalurkan zakatnya kepada BAZNAS Kabupaten Tanah Datar.

Dalam upaya efektivitas program pengumpulan, maka BAZNAS Tanah Datar juga menyebarkan marketing tools sebagai upaya penyadaran masyarakat serta memudahkan bagi muzaki untuk membayarkan zakatnya melalui BAZNAS Kabupaten Tanah Datar. Di antara marketing tools yang dikeluarkan oleh BAZNAS Kabupaten Tanah Datar adalah leaflet, brosur, buletin, kotak zakat, dan sebagainya.

Sosialisasi zakat yang masif kepada seluruh lapisan masyarakat juga terus dilakukan, baik sosialisasi kepada PNS, pengusaha, pedagang, dan masyarakat secara umum. Sosialisasi bertujuan untuk meningkatkan kesadaran dan pertisipasi masyarakat dalam membayar zakat melalui BAZNAS. Sosialisasi itu dilakukan dengan berbagai macam bentuk program, antara lain melalui kajian rutin, dialog interaktif di radio, melalui media sosial, kampanye zakat, dan sebagainya.

\section{PENUTUP}

Daya serap zakat perlu terus ditingkatkan melalui program pengumpulan. Jika potensi zakat mampu diserap secara maksimal maka zakat akan menjadi piranti yang sangat kuat untuk mengentaskan kemiskinan dan meningkatkan kesejahteraan masyarakat. Perkembangan pengumpulan zakat pada BAZNAS Tanah Datar baik dari aspek nominal zakat, sektor zakat, maupun upaya-upaya pengumpulannya akan berdampak positif terhadap pengelolaan zakat secara keseluruhan sehingga berkontribusi dalam mewujudkan visi BAZNAS tersebut yaitu "Menjadi Badan Amil Zakat yang Amanah, Profesional, dan Akuntabel."

\section{DAFTAR KEPUSTAKAAN}

Baga, Lukman Mohammad, 1997. Sari Penting Kitab Fiqih Zakat Yusuf AlQardhawy, Bogor, tp.

Fahham, A. Muchaddam, 2011. Paradigma Baru Pengelolaan Zakat di Indonesia, Journal Kesejahteraan Sosial, Vol.III, No. 19/I/P3DI, Oktober 2011.

Fakhrruddin, 2008. Figh dan Manajemen Zakat di Indonesia, Malang: UINMalang Press.

Fatwa Majelis Ulama Indonesia Nomor 8 Tahun 2011 tentang Amil Zakat, 2011.

Hadi, Muhammad, 2010. Problematika Zakat Profesi dan Solusinya, Sebuah Tinjauan Sosiologi Hukum Islam, Yogyakarta: Pustaka Pelajar.

Hafidhuddin, Didin, 2006. "Dunia Perzakatan di Indonesia," dalam Kuntarno Noor Aflah (ed), Zakat $\mathcal{E}$ Peran Negara, Jakarta: Forum Zakat. 
Mufraini, M. Arief, 2008. Akuntansi dan Manajemen Zakat, cet. ke-2, Jakarta: Kencana.

Muhammad \& Abu Bakar HM, 2011. Manajemen Organisasi Zakat, Malang: Madani.

Ridlo, M. Taufiq, 2006. "Pengelolaan Zakat Di Negara-Negara Islam," dalam Kuntarno Noor Aflah (ed), Zakat \& Peran Negara, Jakarta: Forum Zakat.
Shihab, M. Quraish, 1999. Membumikan alQur'an, cet. XIX, Jakarta: Mizan.

Surur, Naharus, 2006. “Harapan FOZ Terhadap Pengelolaan Zakat di Indonesia," dalam Kuntarno Noor Aflah (ed), Zakat \& Peran Negara, Jakarta: Forum Zakat.

Undang-Undang RI No. 23 Tahun 2011 Tentang Pengelolaan Zakat.

Yani, Dwi, 2008. "Strategi Penghimpunan Dana Zakat," Tesis, Universitas Indonesia. 